\title{
OS LIVROS DA ORDEM TERCEIRA DE SÃO FRANCISCO ENTRE PORTUGAL E A AMÉRICA PORTUGUESA NOS SÉCULOS XVII E XVIII
}

\author{
JULIANA DE MELLO MORAES
}

Fundação Universidade Regional de Blumenau (FURB)

\section{RESUMO}

Este estudo avalia a produção e a utilização de livros entre os franciscanos, com destaque para as obras direcionadas às Ordens Terceiras de São Francisco. Como um importante meio de promoção e difusão da espiritualidade mendicante, os impressos voltados para a comunidade de fieis adquirem um papel relevante, visto que sua leitura e uso ultrapassavam os círculos eclesiásticos, sendo utilizados pelos leigos vinculados à agremiação em distintos territórios, incluindo a cidade de São Paulo. A partir das fontes constata-se a presença e a utilização de obras específicas, editadas em Portugal, no cotidiano e gestão da Ordem Terceira de São Francisco paulistana entre os séculos XVII e XVIII.

PALAVRAS-CHAVE: Ordem Terceira de São Francisco; São Paulo; Portugal; franciscanos; século XVIII.

\section{ABSTRACT}

This study evaluates the production and the use of books among the franciscan, especially the works directed to the Third Orders of Saint Francis. As an important means of propaganda and dissemination of the mendicant spirituality, books directed to the community of believers acquire a relevant role, since their reading and use exceeded the ecclesiastical circles, being handled by the lay tied to the college in different territories, including the city of São Paulo. From the sources is noted the presence and use of specific works, edited in Portugal, in the daily management of the Third Order of St. Francis of São Paulo in the seventeenth and eighteenth centuries.

KEYWORDS: Third Order of St. Francis; São Paulo; Portugal; Franciscans; eighteenth century. 
As disposições emanadas pelo Concílio de Trento (1563), as reformas das ordens religiosas e a formação da Companhia de Jesus (1540), indicavam o esforço múltiplo da Igreja Católica na sua mutação interna, visando, entre outros aspectos, reforçar seus dogmas e atrair os fieis. A adesão às determinações tridentinas pelas monarquias católicas na Península Ibérica, durante o século XVI, avigorava o vínculo, conformado pelo Padroado, entre as Coroas e a Igreja nos empreendimentos de conquista e expansão, incluindo os territórios agregados na América ${ }^{1}$.

Outra medida relevante naquela época desencadeada pela hierarquia eclesiástica, buscando promover o catolicismo entre a população, consistiu na divulgação realizada pelo clero secular e regular das associações de leigos. Esses esforços se refletem nas disposições Sinodais e visitas pastorais portuguesas, as quais sinalizam a interferência do clero para a formação de novas agremiações ${ }^{2}$.

Originárias do medievo, as confrarias, irmandades e Ordens Terceiras, não obstante conheceram um novo impulso no pós-Trento ${ }^{3}$. Essas associações fomentavam um relacionamento mais intenso entre o fiel e a Igreja, através da valorização das devoções, da frequência aos sacramentos, da promoção do auxílio mútuo e da caridade, sob a tutela da hierarquia eclesiástica.

A Ordem dos Frades Menores da Regular Observância de São Francisco (1517), do mesmo modo, participou do movimento de difusão das associações de leigos, promovendo, a partir do início do século XVII, a Ordem Terceira franciscana.

Com Regra aprovada pela Santa Sé em 1289, a Ordem Terceira de São Francisco estava vinculada à Ordem dos Frades Menores da Regular Observância e possuía características normativas aproximadas à dos religiosos, tendo, no entanto, um enquadramento jurídico diverso das irmandades e confrarias. Diferentemente dessas últimas, para adentrar as Ordens Terceiras, era necessário realizar o noviciado, período de formação espiritual dos novos membros, e a profissão, cerimônia que marcava a entrada definitiva do novo membro. A Regra, contendo 16 capítulos, estipulava os requisitos de entrada para os irmãos, as obrigações religiosas, os deveres dos gestores da instituição e o modo de disciplinar os associados. Praticar o jejum, participar da missa,

\footnotetext{
${ }^{1}$ Conforme Boxer "o padroado português pode ser amplamente definido como uma combinação de direitos, privilégios e deveres concedido pelo papado à Coroa de Portugal como patrona das missões e instituições eclesiásticas católicas romanas em vastas regiões da África, da Ásia e do Brasil." BOXER, Charles R. O império marítimo português. São Paulo: Companhia das Letras, 2001, p. 243.

2 De acordo com Pedro Penteado "não existem dúvidas que muitas destas confrarias foram produto da intervenção eclesiástica". PENTEADO, Pedro. Confrarias portuguesas da época moderna: problemas, resultados e tendências da investigação. Lusitânia Sacra. Revista do Centro de Estudos de História Religiosa. Lisboa, 2a série, p. 15-52, 1995.

3 Sobre o crescimento no número das associações de leigos naquele período consultar: PENTEADO, Pedro. Confrarias. In: AZEVEDO, Carlos Moreira (dir.). Dicionário de História Religiosa de Portugal. vol. 1. Lisboa: Círculo de Leitores, 2000, p. 463; MANTECÓN MOVELLÁN, Tomás Antonio. Contrarreforma y religiosidad popular em Cantabria. Las confradías religiosas. Cantabria: Universidad de Cantabria, 1990, p. 1-20.
} 
rezar as horas canônicas, zelar pelos mortos, confessar-se regularmente constavam entre as obrigações dos terceiros franciscanos ${ }^{4}$.

O impulso para a divulgação das Ordens Terceiras franciscanas iniciou a partir das determinações acordadas pelos frades durante o Capítulo Geral realizado em Toledo, Espanha, em 1606, no qual estabeleceram que

la Tercera Orden, que nuestro Serafico Padre São Francisco avia instituido para todos los que viven en sus casas, se predicasse, y se publicasse de nuevo en todas las Provincias de España; para lo qual despachó Letras el Reverendissimo Padre Comissario General Frei Pedro Gonçalez de Mendonza, por todos los Reynos y Provincias de su Familia ${ }^{5}$.

Além de demonstrar a intenção de promover a formação de novas Ordens Terceiras, indicavam-se as formas para realizar tal intento, qual seja, através da pregação e da circulação da palavra escrita. Enquanto o púlpito desempenhava um papel essencial na vivência católica pós-Trento, os manuscritos e impressos também despontavam como veículos fundamentais para a propagação da fé, dos princípios morais e doutrinais da Igreja ${ }^{6}$.

Nessa perspectiva, este estudo avalia a presença e a utilização da palavra escrita - principalmente a impressa - nas instituições franciscanas, privilegiando, entretanto, as obras direcionadas às agremiações de leigos tanto em Portugal quanto na capitania de São Paulo. Como um importante meio de difusão da espiritualidade franciscana, os livros voltados para a comunidade de fieis adquirem papel relevante para a análise, visto que a partir da documentação é possível aferir que a sua leitura e utilização ultrapassavam os círculos eclesiásticos, sendo manipulados pelos leigos vinculados à Ordem Terceira de São Francisco em distintos territórios, incluindo a América portuguesa. Pouco exploradas pela historiografia, principalmente no Brasil, as relações entre impresso e círculos devotos, especialmente nas irmandades,

\footnotetext{
${ }^{4}$ SÃO LUÍS, António. Regra dos irmãos seculares da Santa e Venerável Ordem Terceira da Penitência que instituiu o Seraphico padre São Francisco. Lisboa: Mathias Rodrigues, 1630, p. 59.

${ }^{5}$ ARBIOL, Antonio. Los terceros hijos de el humano serafin. La Venebrable y Esclarecida Orden Tercera de Nuestro Serafico Patriarca San Francisco. Refierese sus gloriosos principios, regla; leyes, estatutos y Sagrados exercicios; sus frandes excelencias, indulgencias, y Privilegios Apostolicos y las vidas prodigiosas de sus principales santos y santas, para consuelo y aprovechamiento de sus amados hermanos. Zaragoza: Pedro Carreras, 1724, p. 60.

${ }^{6}$ Segundo PALOMO, Federico. Cultura religiosa, comunicación y escrita en el mundo ibérico de la Edad Moderna. In: SERRANO MARTÍN, Eliseo (coord.). De la tierra al cielo. Líneas recientes de investigación en Historia Moderna. Zaragoza: Institución «Fernando el Católico»/Universidad de Zaragoza, 2013. p. 63. A respeito da importância da pregação naquele período consultar MARQUES, João Francisco. A palavra e o livro. In: AZEVEDO, Carlos Moreira. (dir.). História Religiosa de Portugal. vol. 2. Lisboa: Círculo de Leitores, 2000, p. 399.
} 
confrarias e Ordens Terceiras, permitem averiguar a importância da palavra escrita na conformação, ordenação e vivência desses grupos ${ }^{7}$.

Os livros direcionados às Ordens Terceiras franciscanas conformavam uma "comunidade de leitores" 8 com regras e práticas de leituras próprias, pautadas na pertença a agremiação. Os impressos religiosos promoviam uma continuidade de concepções e ações, contudo, paralelamente, poderiam desencadear usos e interpretações distintas consoantes ao contexto.

A partir dos livros religiosos identificados na documentação produzida pela Ordem Terceira franciscana de São Paulo, entre os séculos XVII e XVIII, pretende-se averiguar a presença e a utilização da palavra impressa nessas associações, sobretudo naquelas áreas urbanas mais acanhadas e distantes dos centros político-administrativos e econômicos da América portuguesa, consequentemente do império.

As discussões historiográficas a respeito do contexto paulista, entre finais do século XVII e as primeiras décadas do século XVIII, oscilam entre visões de decadência, pobreza e estagnação ou de sedimentação da elite e recrudescimento populacional, revelando perspectivas paradoxais sobre sua economia e população ${ }^{9}$. No entanto, parece coerente afirmar a dinamização da urbe paulista, principalmente após as descobertas auríferas no interior da Colônia, as quais promoveram transformações relevantes nas esferas demográfica, social e econômica ${ }^{10}$. A chegada de imigrantes, sobretudo a partir de 1730, oriundos principalmente do norte de Portugal estimulou 0 desenvolvimento do trato mercantil, fundamentalmente com outras regiões coloniais. O que suscitou alterações na sociedade paulistana, incluso nas instituições da cidade, como a Ordem Terceira de São Francisco ${ }^{11}$.

\footnotetext{
${ }^{7}$ A produção historiográfica sobre a história do livro e dos leitores na América portuguesa é vasta, no entanto não há estudos destinados a avaliar a presença e usos da palavra escrita especificamente nas Ordens Terceiras franciscanas. Dentre a bibliografia sobre a história do livro religioso e leitura na América portuguesa destacam-se: ALGRANTI, Leila Mezan; MEGIANI, Ana Paula (orgs.). O império por escrito. Formas de transmissão da cultura letrada no mundo ibérico séculos XVI-XIX. São Paulo: Alameda, 2009. ABREU, Márcia (org.). Leitura, história e história da leitura. Campinas: Fapesp, 1999.

${ }^{8}$ CHARTIER, Roger. $A$ ordem dos livros. Leitores, autores e bibliotecas na Europa entre os séculos XIV e XVIII. Brasília: Editora Universidade de Brasília, 1999, p. 14.

${ }^{9}$ A propósito das discussões na historiografia sobre São Paulo setecentista consultar SOUZA, Laura de Mello e. O Sol e a Sombra: política e administração na América portuguesa do século XVIII. São Paulo: Companhia das Letras, 2006, p. 109-147; BLAJ, Ilana. Agricultores e comerciantes em São Paulo nos inícios do século XVIII: o processo de sedimentação da elite paulistana. Revista Brasileira de História, São Paulo, vol. 18, n. 36, p. 281-296, 1998; BORREGO, Maria Aparecida de Menezes. A teia mercantil: negócios e poderes em São Paulo colonial (1711-1765). Tese de Doutorado. São Paulo: Universidade de São Paulo, 2006, p. 1035.

${ }^{10}$ BLAJ, Ilana. Op. cit., p. 281-296.

${ }^{11}$ A predominância de comerciantes oriundos do norte de Portugal na América portuguesa é destacada por MONTEIRO, Nuno. As reformas na monarquia pluricontinental portuguesa: de Pombal a dom Rodrigo de Sousa Coutinho. In: FRAGOSO, João; Gouvêa, Maria de Fátima (orgs.). O Brasil Colonial. vol. 3. Rio de Janeiro: Civilização Brasileira, 2014, p. 121; BORREGO, Maria Aparecida de Menezes. Op. cit., p. 36-39. Sobre a Ordem Terceira de São Francisco de São Paulo consultar MORAES, Juliana de Mello. Viver em penitência: os irmãos terceiros franciscanos e as suas associações, Braga e São Paulo (1672-1822). Tese de Doutorado. Braga: Universidade do Minho, 2010.
} 
Nesse sentido, atentar para as características inerentes à difusão e as formas de utilização dos impressos, tendo como referência a filiação à associação vinculada aos mendicantes em São Paulo, possibilita avaliar a circulação do livro em contextos específicos, moldados pela adesão religiosa e sociabilidade desenvolvida nesses espaços. Para tanto foi priorizada a documentação coeva produzida no interior da Ordem Terceira de São Francisco paulistana e os impressos promovidos pelos franciscanos em Portugal. Estes também carecem de análises, pois, como ressalta Federico Palomo,

el asunto ha merecido en general escasa atención historiográfica, sobre todo, si se compara con la centralidad y el carácter casi paradigmático que tradicionalmente se ha atribuido a la escritura jesuítica, en detrimento de otras tradiciones literarias e, incluso, de otros modos posibles de entender y encarar la práctica de la escritura ${ }^{12}$.

Portanto, este estudo sobre a produção bibliográfica franciscana, voltada especialmente para os leigos, e suas conexões entre o Reino e a América portuguesa, investiga uma temática ainda incipiente na historiografia atual.

\section{Os livros entre os mendicantes e irmãos terceiros em Portugal}

A relação estreita das ordens religiosas com a palavra escrita verifica-se desde o medievo, contudo a invenção da imprensa trouxe novas e inéditas possibilidades no seu uso, difusão e consumo. ${ }^{13}$ No que se refere à Igreja, a historiografia enfatizou o papel central do livro entre os protestantes, sendo 0 impresso um marco confessional nesse movimento. Ao sublinhar a propaganda e a difusão da fé através dos livros como um elemento essencial da Reforma, muitas vezes, o papel desempenhado pelos impressos entre os católicos se mostra minimizado ${ }^{14}$. Entretanto, essa perspectiva quanto ao uso da palavra

\footnotetext{
${ }^{12}$ PALOMO, Federico. Conexiones atlánticas: Fr. Apolinário da Conceição, la erudición religiosa y el mundo del impreso en Portugal y la América portuguesa durante el siglo XVIII. Cuadernos de Historia Moderna, Madrid, Anejo XIII, p. 113, 2014.

${ }^{13}$ A respeito das bibliotecas de mosteiros e conventos ver VERGER, Jacques. Homens e saber na Idade Média. Bauru: Edusc, 1999, p. 119. O impacto social provocado pelo desenvolvimento da tipografia desde meados do século XV foi destacado por CHARTIER, Roger. Introdução. A cultura do objecto impresso. In: CHARTIER, Roger (coord.). As utilizações do objecto impresso. Algés: DIFEL, 1998, p. 9-21.

${ }^{14}$ Jonh Bossy, por exemplo, considerou a imprensa como "a mãe da Reforma". Embora o autor sugira a utilização de impressos e a leitura silenciosa entre os católicos desde o século XVI, pouco avança no questionamento ou na desconstrução dessa visão dual referente a protestantes e católicos na utilização da imprensa da época. BOSSY, John. A cristandade no Ocidente 1400-1700. Lisboa: Edições 70, 1990, p. 120-127. Ver também BOUZA ÁLVAREZ, Fernando J. Contrarreforma y tipografía. ¿Nada más que rosarios en sus manos? Cuadernos de Historia Moderna, Madri, n. 16, p. 73-87, 1995.
} 
escrita entre as Igrejas católica e protestante, revela-se já superada na historiografia atual ${ }^{15}$. A renovação das análises dedicadas ao livro e à leitura, nas últimas décadas, além de proporcionar um aprofundamento nas questões e perspectivas sobre a confecção das obras, a sua aquisição pelas populações, a composição das bibliotecas, o mercado editorial, entre outros aspectos, igualmente propôs novas e mais complexas apreciações sobre os fenômenos políticos e religiosos e o consumo de livros ${ }^{16}$. A valorização dos impressos como meio de promoção dos discursos morais e doutrinários ocorreu entre protestantes e católicos desde o século XVI, revelando a acurada percepção do clero das possibilidades da palavra impressa para a difusão da fé ${ }^{17}$.

No que se refere ao universo católico, destaca-se a crescente produção e difusão de livros entre os séculos XVI e XVIII, indicando a grande demanda existente por esses materiais entre os meios eclesiásticos e seculares ${ }^{18}$. A profusão da palavra impressa entre os reinos de Castela, avaliada por Fernando Bouza Álvarez e Federico Palomo, indica a necessidade de considerar a importância do papel e dos textos no contexto do catolicismo pós-tridentino ${ }^{19}$. Embora preservando um índice bastante elevado de analfabetismo, as populações sob as monarquias ibéricas do mesmo modo vivenciaram, ainda que em ritmos distintos de acordo com a região e/ou grupo social, a expansão e a crescente importância da palavra escrita tanto na esfera pública quanto privada naquele período ${ }^{20}$.

O incremento no número de publicações, principalmente de cariz religioso, demonstra a importância destinada à palavra escrita no âmbito do sagrado. A Igreja católica, através das suas mais distintas instituições, considerou as potencialidades da imprensa como meio para propagandear seus dogmas morais e doutrinais após o Concílio de Trento, visando atender tanto seus membros, ou seja o corpo eclesial regular e secular, quanto os seus

\footnotetext{
${ }^{15}$ Ibidem.

${ }^{16}$ Para uma síntese a respeito das transformações na historiografia sobre o livro e a leitura em diferentes países consultar DARTON, Roberto. $O$ beijo de Lamourette. Mídia, Cultura e Revolução. São Paulo: Companhia das Letras, 1990, p. 109-110.

${ }^{17}$ Sobre a propaganda religiosa na França durante o século XVI ler DEYON, Pierre. Sur certaines formes de la propagande religieuse au XVIe siècle. Annales. Économies, Sociétés, Civilisations. n. 1 , p. $16-25,1981$.

${ }^{18}$ Dominique Julia destacou o crescimento no número de publicações de livros religiosos na França, igualmente refere a predominância desses impressos nos inventários de livreiros. JULIA, Dominique. Leituras e Contra-reforma. In: CAVALLO, Guglielmo; CHARTIER, Roger (orgs.). História da leitura no mundo ocidental. São Paulo: Editora Ática, 1999, p. 99.

${ }^{19}$ Segundo PALOMO, Federico. Cultura religiosa, comunicación y escrita en el mundo ibérico de la Edad Moderna. In: SERRANO MARTÍN, Eliseo (coord.). De la tierra al cielo. Líneas recientes de investigación en Historia Moderna. Zaragoza: Institución «Fernando el Católico»/Universidad de Zaragoza, 2013, p. 63. Outras publicações fundamentais sobre a presença do livro religioso entre os católicos, em especial, em Portugal e Espanha são: BOUZA ÁLVAREZ, Fernando J.. Op. cit., p. 73-87; PALOMO, Federico. Misioneros, libros y cultura escrita en Portugal y España durante el siglo XVII. In: CASTELNAU-L'ESTOILE, CH. de; COPETE, M. L., MALDAVSKY, A.; ŽUPANOV, I. G. (eds.). Missions d'évangélisation et circulation des savoirs (XVIe-XVIIIesiècle). Madrid: Collection dela Casa de Velázquez, 2011, p. 131-150.

20 LISBOA, João Luís; MIRANDA, Tiago dos Reis. A cultura escrita nos espaços privados. In: MATTOSO, José (dir.). História da vida privada em Portugal. A Idade Moderna. Lisboa: Círculo de Leitores e Temas e Debates, 2011, p. 339-347.
} 
devotos, animando o mercado livreiro ${ }^{21}$. Tal movimento dinamizado por clérigos e religiosos, do mesmo modo, ocorreu na Península Ibérica. Membros da Igreja participavam ativamente dos processos editoriais seja como autores, intermediários e difusores dos textos escritos, fomentando ainda publicações de variados gêneros (teológico, litúrgico, devocional, histórico, hagiográfico, etc.) $)^{22}$.

Os frades franciscanos colaboraram para a promoção da palavra escrita, utilizando-a para divulgar seus dogmas e devoções, inclusive no intuito de incentivar a formação de novas associações entre os fieis, como referido anteriormente.

Em Portugal, a divulgação das ordens seculares franciscanas resultou da ação promovida por meio da pregação e da difusão da palavra escrita ${ }^{23}$. Inicialmente, a produção de impressos destinava-se fundamentalmente a divulgar a Regra, esse movimento englobou os territórios e reinos pertencentes a monarquia castelhana incluindo Portugal.

Em 1620, era publicada "pela segunda vez", em Lisboa, a Regra dos irmãos seculares da Santa e Venerável Ordem terceira de penitência que instituiu o seráfico padre São Francisco, sob os auspícios de Frei Antônio de São Luís, responsável pela província franciscana portuguesa ${ }^{24}$. A obra foi impressa por Antônio Alvarez, membro da Ordem Terceira franciscana lisboeta, sendo ele também responsável pela sua comercialização disponibilizando o livro para a venda na sua casa situada "ao Poço da Fotea"25. As relações pautadas na devoção comum ao santo de Assis percorreram todas as etapas relacionadas a tal obra, ou seja, a adesão religiosa despontava como uma característica preponderante para a elaboração, impressão, divulgação e comercialização de impressos em Portugal. Do mesmo modo, atesta-se o papel das ordens religiosas, incluindo o seu ramo secular, para o incremento e expansão do mercado livreiro na época.

\footnotetext{
${ }^{21}$ JULIA, Dominique. Op. cit., p. 83.

${ }^{22}$ A respeito da importância dos clérigos e religiosos para a cultura escrita da Idade Moderna, ler PALOMO, Federico. Op. cit., p. 53-88

${ }^{23}$ Sobre a Ordem Terceira franciscana de Lisboa consultar RIBEIRO, Bartolomeu. Os terceiros franciscanos portugueses. Sete séculos da sua história. Braga: Missões Franciscanas, 1952, p. 54.

${ }^{24} \mathrm{Na}$ capa desta edição é referida ser uma segunda impressão, entretanto no livro não há indicações a respeito da publicação anterior, igualmente não foi encontrada em bibliotecas (Biblioteca Nacional de Portugal, Biblioteca Municipal de Braga e Biblioteca Geral de Coimbra) e arquivos portugueses (Arquivo Nacional da Torre do Tombo, Arquivo Distrital de Braga, Arquivo Distrital do Porto) referências sobre a edição anterior. Todavia, foram localizadas outras edições da mesma obra publicadas respectivamente em 1630 e 1669. Bartolomeu Ribeiro menciona uma publicação lisboeta da Regra dos terceiros franciscanos em 1616, entretanto o autor não indica a procedência dessa afirmação. RIBEIRO, Bartolomeu. Op.cit, p. 54. SÃO LUÍS, António. Regra dos irmãos seculares da Santa, e Venerável Ordem terceira de penitencia, que instituiu o seraphico P. S. Francisco. E ordenações gerais para o bom governo da mesma ordem, impressa segunda vez, a instancia do $p$. fr. Antonio de S. Luis difinidor da S. Província de Portugal. Lisboa: Irmão Antonio Alvarez impressor de livros, \& professo da mesma penitência, 1620. ${ }^{25}$ Idem.
} 
Ao longo do século XVIII, o movimento incluiu outras cidades para além da capital portuguesa. No Porto, o mercado livreiro, bastante tímido até 0 século XVII, desenvolveu-se na centúria seguinte, sobretudo a partir de 1750 . A produção e comércio de impressos entre os portuenses concentrava-se a volta de obras de índole moral e religiosa ${ }^{26}$. Um dos livreiros de destaque naquele período foi Manoel Pedroso Coimbra. Ele imprimiu ao menos 42 obras, sendo o seu trabalho diretamente relacionado às instituições religiosas, como o Cabido da Sé, e às agremiações de leigos da cidade, como a Ordem Terceira de São Francisco ${ }^{27}$.

Dentre as obras impressas por Manoel Pedroso Coimbra destaca-se o Compêndio Geral da História da Venerável Ordem Terceira de São Francisco. Este livro publicado em 1752 fora escrito e financiado por Manoel de Oliveira Ferreira, religioso instituído "cronista" da Ordem Terceira pela "Congregação da Rainha Santa Isabel da cidade do Porto"28. Com intenções bastante abrangentes, o texto versava sobre as características particulares da instituição secular franciscana, incluindo o histórico laudatório e defensor da Ordem Terceira a partir de fatos e argumentos considerados dignos de nota, de acordo com as tendências historiográficas da época ${ }^{29}$. Além disso, incluía a Regra bem como as benesses espirituais angariadas pelos seus associados. Embora versasse sobre uma instituição em especial, já na capa o autor elucidava destinar-se a obra a "jurisconsultores, párocos, confessores, pregadores, terceiros de qualquer Ordem, confrades de irmandades e a todo devoto cristão" 30 . Dirigido a universalidade de católicos, detecta-se uma rede mais complexa a volta da idealização e confecção dessa obra, incluindo instituições diversas num projeto comum, qual seja divulgar a ordem secular franciscana através da sua História.

Ainda que direcionados muitas vezes aos membros das Ordens Terceiras de São Francisco, esses livros eram, na mesma medida, necessários aos frades mendicantes. Os acervos bibliográficos das ordens religiosas possuíam diferenças na sua composição de acordo com suas vinculações devocionais, ou seja, variavam as bibliotecas de carmelitas, beneditinos, jesuítas, entre outros ${ }^{31}$. As listas de obras das bibliotecas conventuais franciscanas, tanto ao norte quanto ao sul de Portugal, indicam a presença de impressos sobre as associações de terceiros. No início do século XVIII, o "Rol da livraria da

\footnotetext{
${ }^{26}$ MEIRELES, Maria Adelaide de Azevedo. A actividade livreira no Porto no século XVIII (Contribuição para o seu estudo). Revista de História. Porto, vol. 04, p. 19, 1981.

${ }^{27}$ Idem, p. 8.

${ }^{28} \mathrm{~A}$ instituição reunia irmãs terceiras franciscanas que viviam em clausura, sem contudo realizar todos os votos religiosos. Sobre a Congregação da Rainha Santa Isabel consultar as informações disponíveis em: <http://autoridades.arquivos.pt/producingEntityDetails.do;jsessionid=67EDBE3A2FEEF319170A 5554B4EE6DC1?id=23626>. Data de acesso: 08/09/2014.

${ }^{29}$ Sobre a produção historiográfica no século XVIII ver FALCON, Francisco. História e poder. In: CARDOSO, Ciro Flamarion; VAINFAS, Ronaldo (orgs.). Domínios da História. Ensaios de Teoria e Metodologia. Rio de Janeiro: Campus, 1997, p. 63.

${ }^{30}$ FERREIRA, Manoel de Oliveira. Compendio gera da historia da venerável Ordem Terceira de São Francisco. Porto: Oficina do Capitão Manoel Pedroso Coimbra, 1752.

${ }^{31}$ PALOMO, Federico. Anaqueles de sacra erudición: libros y lecturas de un predicador en el Portugal de mediados del siglo XVII. Lusitania Sacra. Lisboa. n. 18, p. 117-146, 2006.
} 
Congregação de Nossa Senhora de Oliveira do Douro", apesar das lacunas nas informações sobre os livros desse catálogo, indicava três obras dedicadas exclusivamente às Ordens Terceiras: duas inscritas como "a origem da Ordem Terceira" e outra como a "regra" ${ }^{32}$. Também no inventário dos conventuais de São Francisco de Setúbal, no rol referente a sua livraria, organizado por autores, há indicações sobre a agremiação dos terceiros ${ }^{33}$. Essas obras muito provavelmente atendiam as necessidades de alguns religiosos em particular, pois em todos os conventos franciscanos era selecionado um indivíduo, designado de "visitador" ou "padre comissário", o qual era incumbido de instruir e orientar os irmãos terceiros, visitando pelo menos uma vez ao mês as agremiações ${ }^{34}$. As diversas funções desempenhadas pelos membros das ordens religiosas, através de especializações profissionais, tal como os pregadores, suscitava diferentes escolhas bibliográficas entre seus membros, como se verifica, por exemplo, na Companhia de Jesus ${ }^{35}$. No caso dos frades mendicantes, é viável supor que aqueles designados como visitadores das Ordens Terceiras se especializassem na bibliografia referente à instituição.

Desse modo, os impressos produzidos para divulgar e elucidar questões sobre a Ordem Terceira de São Francisco circulavam entre religiosos e leigos, sendo encontrados tanto nas casas conventuais quanto no comércio livreiro das cidades de Lisboa e Porto. Entretanto, essa bibliografia extrapolou os limites do continente europeu, fazendo parte do cotidiano de frades e irmãos terceiros também na América portuguesa.

\section{Os livros da Ordem Terceira franciscana na América portuguesa}

Os estudos sobre a circulação de impressos entre Portugal e a América desenvolveram-se principalmente nas últimas décadas, engendrando publicações de caráter inovador e abrangente, as quais permitem visualizar 0 objeto a partir de distintas perspectivas ${ }^{36}$. Muitas dessas análises baseiam-se

\footnotetext{
${ }^{32}$ ARQUIVO NACIONAL TORRE DO TOMBO (ANTT). Ofm, Província de Portugal, Congregação de N. Sra. da Conceição de Oliveira do Douro, Rol da livraria desta Congregação feito no ano de 1707 por alphabeto ate 0 anno de 1725 , liv. 6, s.p.

$33 \mathrm{O}$ rol da livraria de Setúbal não indica a data ou os títulos apontando somente os autores das obras. ANTT. Ofm, Província dos Algarves, mç. 74, documentos avulsos. s.d. s.p.

${ }^{34}$ SÃO LUÍS, António. Op. cit., p. 13.

${ }^{35}$ PALOMO, Federico. Op. cit., p. 117-146.

36 Dentre esses estudos destacam-se FRIEIRO, Eduardo. $O$ diabo na livraria do cônego. São Paulo: Itatiaia, 1981; SILVA, Maria Beatriz Nizza da. A cultura luso-brasileira. Da reforma da Universidade à Independência do Brasil. Lisboa: Editorial Estampa, 1999; VILLALTA, Luiz Carlos. O que se fala e o que se lê: língua, instrução e leitura. In: SOUZA, Laura de Mello e (org.). História da vida privada no Brasil. vol. 1. São Paulo: Companhia da Letras, 1997. Especificamente sobre a historiografia da história do livro e da leitura no Brasil consultar SILVA, Maria Beatriz Nizza da. História da leitura luso-brasileira: balanços e perspectivas. In: ABREU, Márcia (org.). Leitura, história e história da leitura. São Paulo: FAPESP, 1999; VILLALTA, Luiz Carlos. A história do livro e da leitura no Brasil colonial: balanço historiográfico e proposição de
} 
em documentos elaborados pelos órgãos censores, com destaque para Real Mesa Censória, e os inventários post-mortem, nos quais constam um corolário de obras, oriundas de diversas localidades, circulando na América portuguesa. O envio de livros e impressos para o território americano visava suprir inúmeras necessidades, destacando-se, entretanto, aquelas de cariz profissional, comercial e devocional ${ }^{37}$. Apesar de condizer muitas vezes com o perfil profissional dos seus proprietários, as bibliotecas e também as listas de obras aprovadas pelos censores indicam a presença acentuada de livros religiosos na América portuguesa ${ }^{38}$. A relevância dessas obras naquele contexto demonstrava a vitalidade dessa literatura, sendo esta manipulada por fieis e clero. De fato, as instituições vinculadas à Igreja, bem como as agremiações de leigos, igualmente fomentavam a confecção, distribuição e leitura dessa bibliografia de cunho sagrado. Porém, esse fenômeno é pouco explorado pela historiografia brasileira, exceto para os conventos e recolhimentos femininos tanto no Reino quanto na Colônia ${ }^{39}$. Todavia, como anteriormente destacado, os indivíduos filiados às irmandades, confrarias e, em especial, Ordens Terceiras também faziam uso regular da bibliografia de índole religiosa na época.

Os livros, os impressos e os manuscritos, ou seja, a palavra escrita perpassava o cotidiano das agremiações de leigos, incluindo as Ordens Terceiras de São Francisco, manifestando-se na divulgação das suas devoções, na elaboração e fixação das suas normas de funcionamento e, por fim, nos registros da sua administração cotidiana.

Como na Península Ibérica, muitas ordens seculares franciscanas na América portuguesa formaram-se desde 0 início do século XVII, respectivamente, em 1619, no Rio de Janeiro; em 1635, na Bahia; em 1641, em Santos; em 1646, São Paulo ${ }^{40}$. O período de ereção dessas associações,

uma pesquisa sobre o romance. In: ABREU, Márcia (org.). Trajetórias do romance. Circulação, leitura e escrita nos séculos XVIII e XIX. São Paulo: FAPESP, 2008.

37 SILVA, Maria Beatriz Nizza da. Op. cit., p. 129-182; NEVES, Lúcia M. Bastos Pereira das. Comércio de livros e censura de ideias: a atividade dos livreiros franceses no Brasil e a vigilância da mesa do Desembargo do Paço. Ler História, Lisboa, n. 23, p. 61-78, 1992; VILLALTA, Luiz Carlos. Os leitores e os usos dos livros na América portuguesa. In: ABREU, Márcia (org.). Leitura, história e história da leitura. São Paulo: FAPESP, 1999; ALGRANTI, Leila Mezan. Livros de devoção, atos de censura. Ensaios de História do livro e da leitura na América portuguesa (1750-1821). São Paulo: HUCITEC/FAPESP, 2004.

${ }^{38}$ A entrada de livros na Colônia englobava não somente materiais aprovados pelos censores, mas também livros proibidos que eram contrabandeados para a região. A respeito consultar: idem, p. 168-169; VILLALTA, Luiz Carlos. Op. cit., p. 200; SILVA, Maria Beatriz Nizza da. Op. cit., p. 154.

${ }^{39}$ Dentre esses estudos destacam-se BELLINI, Lígia. Cultura escrita, oralidade e gênero em conventos portugueses (séculos XVII e XVIII). Tempo, n. 29, p. 211-233, 2010; ALGRANTI, Leila Mezan. Op. cit.; GANDELMAN, Luciana. Estatutos, visitas, memórias e atas: a construção da norma nos recolhimentos de Órfãs administrados pelas Misericórdias no século XVIII. In: ALGRANTI, Leila Mezan; MEGIANI, Ana Paula (orgs.). O império por escrito. Formas de transmissão da cultura letrada no mundo ibérico séculos XVI-XIX. São Paulo: Alameda, 2009, p. 96.

${ }^{40}$ As datas de fundação das Ordens Terceiras de São Francisco na América portuguesa constam na tese de MARTINS, William de Souza. Membros do corpo místico: Ordens Terceiras no Rio de Janeiro (1700-1822. vol. I. Tese de Doutorado. São Paulo: Universidade de São Paulo, 2001, p. 69-83. Apesar de 1646 ser a data aceita pela historiografia brasileira, no arquivo privado da Ordem Terceira franciscana de São Paulo só é possível identificar documentação produzida a 
concomitante a Portugal, demonstra a eficácia na divulgação exercida pelos frades mendicantes, pois tal movimento rapidamente atravessou o Atlântico, angariando a receptividade dos fieis de além-mar, incluindo os habitantes de São Paulo.

No período de fundação da ordem secular em São Paulo, as dimensões acanhadas da urbe e, principalmente, a proibição da instalação de imprensas na América portuguesa são alguns fatores para justificar a escassez de livros na região ${ }^{41}$. Tal afirmação se constata pela inexpressividade dos impressos nos inventários paulistas produzidos entre 1578 e 1700, onde foram localizadas somente 55 obras $^{42}$.

Tal cenário, no entanto, alterou-se significativamente durante o século XVIII. As possibilidades de enriquecimento, por meio da mineração, estimularam a imigração na América portuguesa, não somente para os núcleos mineradores, mas igualmente para outras áreas, incluindo São Paulo. Ali as taxas referentes a população indicam crescimento acelerado entre 1690 e 1765, calculado em $435 \%$, revelando a dinamização da urbe naquele período ${ }^{43}$. A partir de São Paulo seguiam "comerciantes e seus carregamentos com o intuito de levar gêneros alimentícios, produtos coloniais e importados do Reino, animais e escravos africanos aos habitantes das minas ${ }^{\prime \prime 4}$. Algumas características marcavam esse grupo voltado para o trato mercantil, tais como a sua origem geográfica (norte de Portugal) e o conhecimento da leitura e escrita (alfabetização) $^{45}$. Tal grupo disputou com a elite terratenente os cargos de prestígio nas instituições da cidade, como a Câmara Municipal ou a Ordem Terceira franciscana ${ }^{46}$. Essa última recebeu grande adesão dos comerciantes, os quais angariaram ampla representatividade no órgão gestor da associação, representando $37 \%$ dos seus gestores, entre 1714 e $1799^{47}$.

Naquele período, os livros religiosos, principalmente de cariz devocional, figuravam entre os estoques das lojas e nas bibliotecas particulares dos comerciantes em São Paulo, demonstrando a disponibilidade desses materiais

partir de 1674. Sobre a fundação da ordem secular, ver ORTMANN, Adalberto. História da antiga capela da Ordem terceira da Penitência de São Francisco em São Paulo. Rio de Janeiro: Publicações do Patrimônio Histórico e Artístico Nacional (DPHAN), 1951, p. 17; ARQUIVO DA ORDEM TERCEIRA DE SÃO FRANCISCO DE SÃO PAULO (AOTFSP). Livro de termos $n^{\circ} 1, \mathrm{fl} .2$.

41 A proibição da instalação de imprensas na América portuguesa recebeu a atenção de HOLANDA, Sérgio Buarque. Raízes do Brasil. 26 ed. São Paulo: Companhia das Letras, 1995. Sobre a escassez de livros na América portuguesa consultar VILLALTA, Luiz Carlos. Op. cit., p. 186-187.

${ }^{42}$ MACHADO, Alcântara. Vida e morte do bandeirante. Belo Horizonte: Editora Itatiaia, 1980, p. 103-104.

${ }^{43}$ A respeito do crescimento demográfico de São Paulo ler MARCÍLIO, Maria Luiza. Crescimento demográfico e evolução agrária paulista 1700-1836. São Paulo: Hucitec, 2000, p. 71.

${ }^{44}$ BORREGO, Maria Aparecida de Menezes. Op. cit., p. 18.

45 A respeito do perfil dos emigrantes ligados ao comércio na América portuguesa ler MONTEIRO, Nuno. Op. cit., p. 120-121.

${ }^{46}$ BLAJ, Ilana. Op. cit., p. 281-296.

47 MORAES, Juliana de Mello. Op. cit., p. 416-420. 
para a população ${ }^{48}$. Um desses comerciantes foi Manoel Soares de Carvalho, membro da Ordem Terceira franciscana, que participou ativamente da administração do sodalício em $1756^{49}$. Ele possuía em sua morada 10 livros, dentre os quais dois produzidos na esfera mendicante: Sumário dos frades menores e o Tesouro Espiritual Seráfico ${ }^{50}$. A seleção e aquisição de obras por Manoel Carvalho pautou-se nas suas devoções e círculos de sociabilidades, ou seja, a partir da sua vinculação à associação de irmãos terceiros franciscanos. Paralelamente a posse desses impressos pelo comerciante corrobora a afirmação de que muitos dos indivíduos ligados ao trato mercantil na cidade eram alfabetizados.

Outros indivíduos em contato regular com a palavra escrita eram os gestores das Ordens Terceiras franciscanas. Eles deveriam seguir os preceitos tanto da Regra quanto dos seus estatutos particulares, os quais adequavam as normas gerais ao contexto de cada agremiação. Sob essa pluralidade normativa geriam-se as múltiplas ações desenvolvidas pela instituição, desde os ritos fúnebres até a atividade creditícia ${ }^{51}$.

As publicações elaboradas pelos franciscanos faziam parte dos acervos das associações seculares, inclusive em São Paulo ${ }^{52}$. Tais impressos eram manipulados no interior das instituições, em especial a Regra, pois, de acordo com as determinações do órgão gestor, os novos membros não seriam admitidos "sem saberem a regra", devendo "decorar ou toda ou parte dela para exame"53. Infelizmente, as fontes são lacônicas sobre as práticas de leitura e a recepção dos impressos entre a generalidade dos irmãos no cotidiano da Ordem Terceira paulistana. Entretanto, a imposição de "decorar" os preceitos da Regra para adentrar a associação exigia que os alfabetizados a lessem ou que os analfabetos a ouvissem a ser lida pelo mestre de noviços. A leitura em voz alta, comumente praticada nos conventos femininos, servia para instruir as religiosas, sendo, muito provavelmente, utilizada entre os irmãos terceiros para transmitir as disposições normativas aos noviços ${ }^{54}$. Ademais, deve-se relativizar os distanciamentos entre a palavra escrita e a oral, essas não se constituem em esferas completamente estanques, já que a escrita exerce influência sobre a expressão oral ${ }^{55}$.

Contudo, não somente no momento de admissão de um novo membro, observa-se a presença e valorização dos impressos entre os seculares

\footnotetext{
${ }^{48}$ BORREGO, Maria Aparecida de Menezes. Entre as fazendas da loja e os trastes da casa: os livros dos agentes mercantis em São Paulo setecentista. In: ALGRANTI, Leila Mezan; MEGIANI, Ana Paula (orgs.). O império por escrito. Formas de transmissão da cultura letrada no mundo ibérico séculos XVI-XIX. São Paulo: Alameda, 2009, p. 236-237.

${ }^{49}$ AOTFSP. Livro das eleições (1714-1799), fl. 70.

${ }^{50}$ BORREGO, Maria Aparecida de Menezes. Op. cit., p. 248.

51 Sobre a "pluralidade de instrumentos normativos" nas instituições do período consultar GANDELMAN, Luciana. Op. cit., p. 96.

${ }^{52}$ AOTFSP. Livro de assento e inventário das alfaias da Venerável Ordem do Seraphico São Francisco, fl. 17v.

${ }^{53}$ AOTFSP. Livro das recepções (1695), fl. 1.

${ }^{54}$ A respeito da instrução religiosa por meio da leitura coletiva da palavra impressa consultar ALGRANTI, Leila Mezan. Livros de devoção, atos de censura. Ensaios de História do livro e da leitura na América portuguesa (1750-1821). São Paulo: HUCITEC/FAPESP, 2004, p. 51.

${ }^{55} \mathrm{~A}$ respeito das relações entre oralidade e letramento consultar BELLINI, Lígia. Op. cit., p. 219.
} 
franciscanos. Dentre a documentação produzida pelos irmãos terceiros encontram-se registros indicando o uso de livros em outras ocasiões. Em 1759, durante uma discussão sobre a quantidade de missas celebradas aos falecidos, foi mencionada a bibliografia produzida pelos franciscanos em Portugal. Os debates a respeito das celebrações litúrgicas destinadas aos defuntos demandavam grande atenção, visto que essas instituições tinham dentre suas principais finalidades garantir aos seus membros assistência no momento da morte, assegurando aos seus associados inumação e ritos de acordo com os parâmetros estipulados pela Igreja católica ${ }^{56}$. Além disso, as celebrações fúnebres denotavam às associações visibilidade tornando-se foco de prestígio social $^{57}$.

As discussões a respeito dos ritos fúnebres entre os gestores da ordem secular ocorreram em distintos momentos, no entanto destaca-se inicialmente um acordo realizado em 1692. Neste os irmãos terceiros determinaram, além das 12 missas celebradas por cada membro falecido, "que conforme o capitulo da regra era todo irmão ou irmã obrigado a mandar dizer 3 missas cada ano e porque todos não satisfação esta obrigação toma a ordem sobre si esta satisfação" ${ }^{\prime 58}$. A referida obrigação das três missas, indicada pelos administradores da Ordem, não corresponde aos preceitos da Regra, nem às determinações dos seus estatutos confeccionados em $1686^{59}$. Verifica-se, portanto, algum desconhecimento entre os seculares franciscanos tanto das disposições gerais, contidas na Regra, quanto daquelas de caráter particular da associação em São Paulo, decorrência, provavelmente, da falta de livros e impressos na região naquele período.

Os esforços dos irmãos terceiros para incrementar os sufrágios justificavam-se devido a crença de que a salvação das almas dependia tanto do esforço individual quanto do coletivo. Nesse contexto as associações de leigos desempenhavam um papel relevante, pois era essencial o envolvimento de distintas esferas, tanto pessoal quanto coletiva, visto que dificilmente a boa morte seria possível na solidão ${ }^{60}$. Desse modo, indivíduo e comunidade contribuíam para o bem morrer, sendo os receios e temores em relação ao destino da alma razões significativas para os fieis associarem-se em vida às agremiações e dedicarem, no momento da morte, grande parte de suas finanças às instituições religiosas. Para garantir a expiação dos pecados, no intuito de abreviar a purgação, as pessoas estabeleciam celebrações litúrgicas

${ }^{56}$ ARAÚJO, Ana Cristina. A morte em Lisboa. Atitudes e representações 1700-1830. Lisboa: Editorial Notícias, 1997, p. 320.

57 De acordo com REIS, João José. A morte é uma festa. Ritos fúnebres e revolta popular no Brasil do século XIX. São Paulo: Companhia das Letras, 1999, p. 144.

${ }^{58}$ AOTFSP. Livro de termos e estatuto, fl. 183v. A ata não revela qual edição da Regra foi utilizada.

${ }^{59}$ AOTFSP. Livro de termos e estatuto, fls. 3-10.

${ }^{60}$ A dualidade na vida católica entre comunidade e indivíduo e a necessidade destas duas esferas na vivência religiosa de antanho foi analisada por LEBRUN, François. As reformas: devoções comunitárias e piedade individual. In: ARIÈS, Philippe; DUBY, Georges (dir.). História da vida privada. Da Renascença ao século das Luzes. vol. 3. Porto: Afrontamento, 2000, p. 92. 
que, muitas vezes, se perpetuavam no tempo ${ }^{61}$. A missa, como celebração expiatória, constituía-se no principal mecanismo para a salvação das almas, pois, desde o século XIII, representava o momento em que "o Cristo ora, e o seu sangue são as esmolas" ${ }^{\prime 62}$.

As preocupações com as cerimônias, principalmente com os ritos fúnebres, ocupavam sobremaneira os irmãos seculares, seja pela sua relevância social ou devido ao necessário investimento financeiro para sua concretização ${ }^{63}$. Nessa perspectiva, constituía-se fundamental estipular a quantidade de celebrações litúrgicas destinadas aos defuntos de forma adequada. Entretanto, as discussões a respeito dos ritos fúnebres entre os irmãos terceiros paulistanos alteraram-se ao longo tempo, revelando uma aproximação as determinações gerais contidas na bibliografia produzida pelos franciscanos em Portugal.

Diferentemente do final do século XVII, novos argumentos foram expressos na reunião do órgão gestor sobre o número de missas destinadas aos falecidos em 1759. As decisões estabelecidas naquele ano indicam que os gestores confrontaram os livros produzidos pelas gestões anteriores e a bibliografia destinada às Ordens Terceiras franciscanas. Nas atas registraram a consulta ao "termo lavrado aos 2 de fevereiro de 1692" e a Regra contida no "Compendio geral da historia da nossa Venerável Ordem" de autoria do "reverendo doutor Manoel de Oliveira Ferreira"64. Embora não seja aludida à edição é provável tratar-se da publicação portuense de 1752, estando sua aquisição e uso possivelmente relacionada à origem de muitos irmãos terceiros, qual seja, o norte de Portugal. Em contraste com as decisões do século anterior, o livro despontava como autoridade e justificava a redução no número de missas celebradas pelos defuntos, pois "só nos manda rezar cada ano com padre nosso com réquiem no fim por todos os nossos irmãos defuntos"65. Portanto, a diminuição da quantidade de sufrágios, anulando disposições internas, baseou-se nas normas gerais, as quais mostraram-se mais adequadas para o órgão gestor naquele momento.

Nesse sentido, os incentivos iniciais de divulgação da Regra do início do século XVII, ainda que tenham colaborado para novas fundações, não garantiram inicialmente a efetiva implementação das suas disposições nas novas associações. Especialmente naquelas regiões onde a presença dos livros e da alfabetização eram precárias, como São Paulo, as referências aos preceitos da Regra não corresponderam a sua aplicação efetiva no cotidiano da instituição. Entretanto, ao longo do século XVIII, a propagação de impressos e livros determinou a aproximação da população com a palavra escrita, suscitando novas interpretações, tal como se verifica na Ordem Terceira de São Francisco. As adaptações normativas da instituição, seja através da elaboração

${ }^{61}$ A respeito das missas solicitadas pelos testadores lisboetas ler ARAÚJO, Ana Cristina. Morte. In: AZEVEDO, Carlos Moreira (dir.). Dicionário de História Religiosa de Portugal. vol. 3. Lisboa: Círculo de Leitores, 2000, p. 273.

62 LE GOFF, Jacques. O nascimento do purgatório. Lisboa: Estampa, 1993, p. 362.

${ }^{63}$ Sobre os gastos avultados com cerimônias religiosas nas Ordens Terceiras ver MORAES, Juliana de Mello. As celebrações nas igrejas da ordem terceira de São Francisco: festas e cultura entre os seculares franciscanos no Império português, século XVIII. Horizonte. Belo Horizonte, v. 9, n. 21, p. 306-320, 2011.

${ }^{64}$ AOTFSP. Livro II de termos, fl. 30v.

${ }^{65}$ AOTFSP. Livro II de termos, fl. $30 \mathrm{v}$. 
de estatutos próprios ou das disposições emanadas pelos órgãos gestores, pautaram-se na bibliografia franciscana. Todavia, distanciamentos e aproximações marcaram essa relação entre os gestores e os livros direcionados à instituição. Nesse sentido, o uso do livro como autoridade não somente transparecia para determinar a priori as práticas religiosas, mas também poderia ser utilizado para desviar disposições dantes estabelecidas no interior das instituições ${ }^{66}$. A aplicação e a conformação das normas atendiam conjunturas particulares, suprindo necessidades específicas de acordo com contextos sociais e econômicos, porém essa dinâmica também parece depender da presença mais ou menos acentuada de livros na sociedade.

\section{Considerações finais}

A produção historiográfica dedicada a história do livro religioso e da leitura para os territórios do império português tem destacado a Companhia de Jesus ou as ordens femininas em detrimento de outras filiações religiosas. Não obstante, análises recentes privilegiam a produção, distribuição e circulação de impressos protagonizadas pelos membros da ordem franciscana, indicando a relevância do fenômeno no contexto ibérico e americano. As conexões entre Portugal e América portuguesa através da circulação de livros de índole religiosa, oriundos da esfera mendicante, não estavam circunscritas, entretanto, aos frades. Os leigos, através da sua vinculação às Ordens Terceiras, igualmente participaram desse movimento, tomando parte na confeç̧ão, difusão e comércio das obras elaboradas pelos franciscanos em Portugal, bem como na sua distribuição seja no Reino ou na Colônia.

A bibliografia produzida na orbe franciscana poderia ser encontrada tanto entre os frades quanto entre os irmãos terceiros nas mais diversas localidade do império português. A presença desses livros nos acervos de bibliotecas conventuais portuguesas, bem como entre os objetos inventariados na Ordem Terceira paulistana, revela a circulação de obras no interior da família franciscana independente da sua localização.

A cidade de São Paulo, ainda que afastada dos centros econômicos e políticos do império, durante o século XVIII, contou com o incremento da circulação de impressos, especialmente da literatura de cariz religioso, a qual orientava o cotidiano das instituições, tal como a Ordem Terceira de São Francisco ${ }^{67}$. Nessa a necessidade de seus novos afiliados decorarem os preceitos da Regra, evidenciava o valor angariado pela palavra escrita naquelas agremiações. Contudo, essa valorização do corpus normativo e da sua aplicação

${ }^{66}$ Sobre a "produção da norma" nas instituições do período consultar GANDELMAN, Luciana. Op. cit., p. 95-110.

${ }^{67}$ A respeito das obras e bibliotecas em São Paulo no século XVIII consultar BORREGO, Maria Aparecida de Menezes. Op. cit., p. 242-252. 
variaram segundo necessidades ou conjunturas específicas, adaptando-se aos contextos e às condições circundantes.

A partir da análise de fontes coevas identifica-se, portanto, a presença de circuitos específicos de publicação e utilização de livros, muitas vezes, não abordados pelos estudos voltados para a circulação de impressos naquele período. Essa premissa corrobora afirmações historiográficas que apontam para a necessidade de rever a "escassez absoluta de livros e leitores" na América portuguesa, pois distintas instituições religiosas, incluindo as Ordens Terceiras de São Francisco, fomentavam o contato da população com a palavra impressa ${ }^{68}$.

\section{Sobre a autora}

Juliana de Mello Moraes é docente de História na Fundação Universidade Regional de Blumenau (FRUB). Pesquisadora no núcleo de investigação em Turismo, Cultura e Território (TERRITUR), Centro de Estudos Geográficos/Instituto de Geografia e Ordenamento do Território, da Universidade de Lisboa. Doutora em História pela Universidade do Minho (Portugal). Mestre e graduada em História pela Universidade Federal do Paraná. Tem experiência na área de História, com ênfase em História da América do século XVII ao XIX, atuando principalmente nos seguintes temas: religiosidade, instituições no Período Moderno e intercâmbios culturais no mundo Atlântico. Realizou o pós-doutorado na Universidade de Lisboa.

Artigo recebido em 15 de novembro de 2014.

Aprovado em 05 de dezembro de 2014.

\footnotetext{
${ }^{68}$ A necessidade de rever as afirmações na historiografia sobre a escassez de livros na Colônia foi ressaltada por ALGRANTI, Leila Mezan. Op. cit., p. 166-167.
} 